\title{
Enterprise Development with P Systems
}

\author{
Xiuting Li, Laisheng Xiang, Xiyu Liu \\ Management Science and Engineering \\ Shandong Normal University \\ Shandong, Jinan \\ China \\ sunnysddy@126.com, sunnysddy@gmail.com
}

Received: June 12, 2019. Revised: June 27, 2021. Accepted: October 5, 2021. Published: November 26, 2021.

\begin{abstract}
Enterprises are both an emerging force in national reform and a major force in its future economic development. The professors in China and on abroad have do much research on enterprise development and put forward lots of valuable theories. $P$ systems have been proposed for about 14 years, and its applications refer to numbers of areas. However, to investigate the survival and development of firms in the aspect of $P$ systems is rarely. In this study, it makes analysis on the survival and development of small and medium-sized enterprises in an aspect of bionics, trying to find out the origin which makes the enterprise exuberant and everlasting. Have the enterprises compare to biological cells and construct a membrane framework in order to interpret an enterprise's survival. At the same time it also highlights the irreplaceable role of enterprise DNA in the inheritance of the enterprise entity.
\end{abstract}

Key-Words: Enterprise Cell, Enterprise DNA, P Systems, Bionics

\section{INTRODUCTION}

Development of small and medium-sized enterprises (SMEs) is essential to development of national market economy. And SMEs are becoming the most vital growth point in national economy and the important part in socialist market economy. Researches on how enterprise survive, develop and evolve are always a main stream of enterprise theory study since the born of enterprise. Management has gone through several stages: Traditional experience management, Classical science management, Behavior science management and Culture management. Why there is more short-lived cooperates than longevous? More out-of-order ones than ordered? More tired entrepreneurs than relaxed? Various theories give numerous explanations while the problem has not been solved very well. Based or analyzing the basic theory of regarding enterprises as living organism is always been there, because we see them really like an organism with life, living or die, old or young, healthy or sick, and there's life cycle fluctuation. Now, it is the stage of Bionic Management.
The smallest unit of an organism is cells rather than people, so enterprises can be visualized as a cluster of cells. On the basis of these studies, SMEs are basically the structure of cells, and the functions can be compared to cells metabolism. They have the similar enterprise DNA and similar development patterns. Along with Darwin's theory of evolution, only the strong survive and evolve constantly.

Without coevolution, there's only sacrifice and so does the enterprises' inner competition and cooperation. This kind of cell rules decide the rules of people and then decide the rules of enterprise development can be called enterprise cytology. Based on the summary of theory and literature of both domestic and overseas bionic management scholars, plus effects of enterprises got after adoption of bionic management, it is believed that the research and application of bionic management is in a new level, which can be proved to be scientific and practical, which can bring economical and social value, which is in compliance with harmonious coordination of people and society.

In this study, we put SMEs in line with $\mathrm{P}$ systems and construct a cell framework of enterprise in order to illustrate some concepts in angle of $\mathrm{P}$ systems. With membrane computing's rapidly development, the theories of bionics enterprise management will get a wide vista.

\section{ENTERPRISE BIONICS AND P SYSTEMS}

\section{A. Enterprise Bionics Theory}

Until now, there's no certain conclusion on what enterprise bionics is and its research methods and series of related concepts. In the study we consider enterprise bionics as a new management pattern on 
enterprises' mechanism, which simulates living beings so that to make new design on its structure and function with the purpose of healthy development. It derives from culture management, but has more meanings beyond culture management. It becomes more specific, more maneuverability, and more practical, dealing with basic issuers from the point of mechanism. Properly to handle the relationships between persons, enterprises, society and the environment may be the realization of enterprise's longevity.

There is a great deal of researches concerning the theory of enterprise bionics. The American scholar entrepreneur Ken Baskin(2001) holds up the concept of market ecology, organic company, and synergism evolution hypothesis. His book mirrors the origination of organism system over these years, and exposes the basic motivity of business development. Meanwhile he points that corporate organizational model needs to transfer to organic model, and let company be an organic being ${ }^{[1]}$. The insufficient is not expounding the realizing pathway on transferring to organic pattern in detail; and not anatomizing the structure and function of operating mechanism. Neilson et. al(2004) defines the basic factor of enterprise is enterprise DNA, just the same as a person is decided by a series of complicated genes, the enterprise DNA controls the enterprise gene $^{[2]}$. Professor Li(2007) studies the enterprise evolution process from the aspect of enterprise genes and thinks that genes self-organization is the basic mechanism of enterprise evolution. He also points out this mechanism contains the DNA replication, differentiation, recombination and diagnosis-four mechanisms ${ }^{[3]}$. The analysis is a great progress but penetrate less deeply. Prof. Qian(2008) raises the synergism relationship between econiche and environment, and puts forward the mainly moving force of evolution is the combination of creative and environment selection mechanism $^{[4]}$. However the reference of the relationship between organic beings and life of enterprises is not sufficient. The research delicacy is much in broad outline and there needs more deeply investigation. Chen(2009) compares enterprise to human systems-nervous system, circulatory system, respiratory system, digestive systems, immune system etc $^{[5]}$. It is valuable for making a systemically comparative research. Liu(2011) studies the innovative small and medium-sized enterprises' genes, identifies its structure and analyses its activities ${ }^{[6]}$. He constructs a unity of theoretical framework so that deepens the effect of enterprise genes on its growth of internal mechanism theory research.

\section{B. P Systems Research}

Membrane computing is an emergent branch of natural computing, first introduced by Păun [7]. This unconventional model of computation is a type of distributed parallel system, which is inspired by the structure and function of living cells. The devices of this model are called P systems. Roughly speaking, a P system consists of a cell-like membrane structure, in the compartments of which there are multisets of objects that evolve according to given rules in a synchronous, non-deterministic maximally parallel manner. Many different classes of such computing devices have already been investigated. Most of them are computationally universal, i.e., able to compute whatever a Turing machine can do, and are computationally efficient, i.e., able to trade space for time and in this way solve presumably intractable problems in a feasible time. Membrane computing is very attractive from a computational point of view because of its hierarchical structure and intrinsic parallelism. In this paper, several basic notions of membrane computing are introduced. For more information, refer to [8-9]. The membrane structure of a $\mathrm{P}$ system, shown in Figure 2-1, consists of several membranes arranged in a hierarchical structure inside a main membrane, called the skin. A membrane without any other membranes inside is said to be elementary. A space delimited by one membrane and its immediately lower membranes is called a region, and the region of an elementary membrane is the space delimited by it. Each region can contain a multiset of objects and a set of evolutionary rules, by which objects can evolve, and communication rules, by which objects can be moved between regions. 


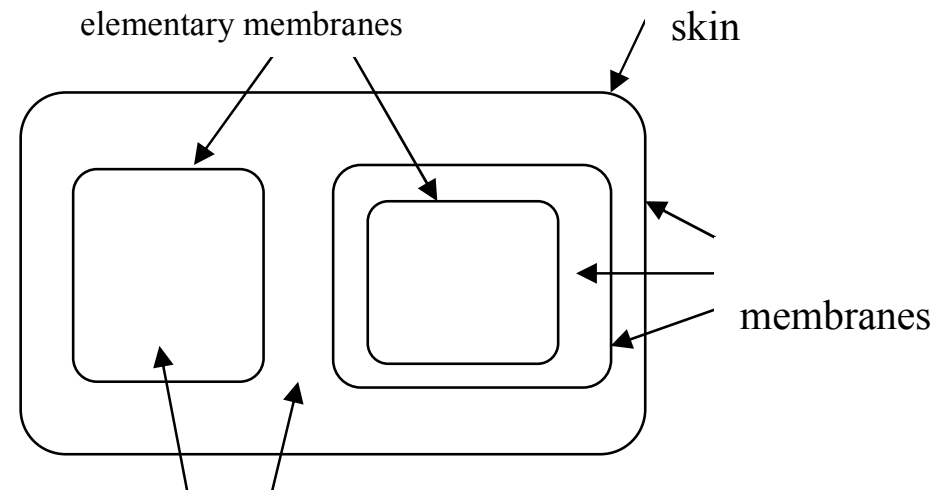

regions

Fig.2-1 Membrane Structure

A P system can be defined as follows:

$\Pi=\left(\mathrm{O}, \mu, w_{1}, \cdots, w_{n},\left(R_{1}, \rho_{1}\right), \cdots\left(R_{n}, \rho_{n}\right), i_{0}\right)$,

Where,

(i) $\mathrm{O}$ is an alphabet of objects, its elements are called objects;

(ii) $\mu$ is a membrane structure consisting of $n$ membranes (and hence the regions) injectively labeled with $1,2, \cdots, n, n \geq 1$;

(iii) $w_{i}$ are strings that represent multisets over $\mathrm{O}$;

(iv) $R_{i}$ are finite sets of evolution rules;

(v) $\rho_{i}$ are a partial order relation on $R_{i}$;

(vi) $i_{0}$ is the output membrane.

Some basic rules are:

endocytosis rule: $[\mathrm{u}]_{i}[]_{j} \rightarrow\left[[v]_{i}\right]_{j}$

exocytosis rule: $\left[[\mathrm{u}]_{i}\right]_{j} \rightarrow[v]_{i}[]_{j}$

evolution rule: $[u \rightarrow v]_{i}$

divide rule: $[\mathrm{u}]_{i} \rightarrow[v]_{j}[w]_{k}$

reproduction rule: $[u]_{i} \rightarrow[]_{i}[u]_{j}$ dissolve rule: $[\mathrm{u}]_{i} \rightarrow v$

creation rule: $u \rightarrow[v]_{i}$

communication rules: sending in: $u[]_{i} \rightarrow[v]_{j}$ sending out: $[u]_{i} \rightarrow[]_{j} v$

\section{CONSTRUCT THE ENTERPRISE CELL MEMBRANE STRUCTURE}

\section{A. Basic Enterprise Cell Membrane Structure}

In the view of enterprise bionics, enterprises also have there life just like any other livings. They have the process of birth, growth, strong, and finally go to die. Considering enterprises as the "cells" of market economy, so enterprises have the structure of $\mathrm{P}$ systems. We define a small and medium-sized enterprise as:

Enterprise $=\left(\mathrm{O}, \mu, w_{i}, \cdots, w_{n},\left(R_{i}, \rho_{i}\right), \cdots\left(R_{n}, \rho_{n}\right), i_{0}\right)$ Where,

(i) $\mathrm{O}$ is an alphabet of objects, its elements are strategy, resource, team, vision and its components respectively;

(ii) $\mu$ is an enterprise basic structure consisting of $n$ membranes (and hence the regions) injectively labeled with $1,2, \cdots, n, n \geq 1$;

(iii) $w_{i}$ are strings that represent multisets over $\mathrm{O}$, as enterprise DNA in vision membrane, we write $w_{6}=$ enterprise $D N A$;

(iv) $R_{i}$ are finite sets of evolution rules, as mentioned upwards, $u \rightarrow[v]_{i}$ can be used to express the creation of an enterprise; $[\mathrm{u}]_{i} \rightarrow v$ is the dissolve of an enterprise; $u[]_{i} \rightarrow[v]_{j}$ and $[u]_{i} \rightarrow[]_{j} v$ are rules to interpret the communication and exchange process between firms; resources' transformation is the rule $[u \rightarrow v]_{i}$ and $[\mathrm{u}]_{i} \rightarrow[v]_{j}[w]_{k}$; to create a subsidiary firm $\left[[\mathrm{u}]_{i}\right]_{j} \rightarrow[v]_{i}[]_{j}$ can be used; and company's merger 
and restructuring is in explanation with

$$
[\mathrm{u}]_{i}[]_{j} \rightarrow\left[[v]_{i}\right]_{j} \text {; }
$$

(v) $\rho_{i}$ is a partial order relation on $R_{i}$;

(vi) $i_{0}$ is the outside market environment.

We calculate the basic structure of enterprise cell as the figure:

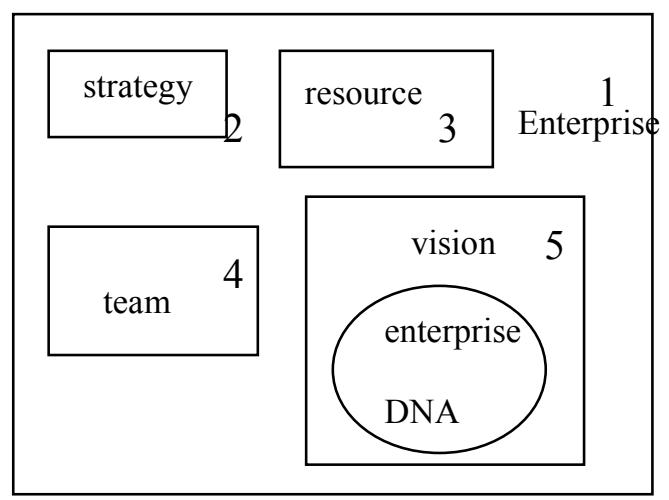

environme

Fig.3-1 Membrane Structure of Enterprise Cell

There are 6 membranes, and we show it as: $\left[{ }_{1}[2]_{2}\left[{ }_{3}\right]_{3}[4]_{4}\left[5[6]_{6}\right]_{5}\right]$. Membrane 1 is the skin membrane that separate the enterprise from the market environment; membrane 2 is the strategy membrane, it consists of 3 elementary membranes: developing strategy, competing strategy and talents(Fig.3-2(a)); membrane 3 is the resource membrane, it also include-human resources, material resources, financial resources(Fig.3-2(b)) three kind of resources; team membrane is labeled with 4 , there are: core leadership layer, backbone layer and ordinary employees layer(Fig.3-2(c)); membrane 5 is the vision membrane, the enterprise DNA is included(Fig.3-2(d)).

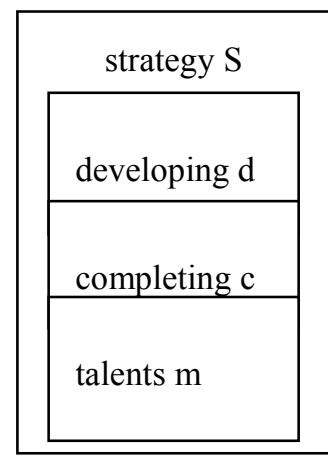

(a)

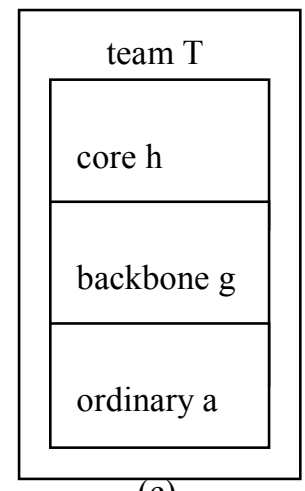

Fig.3-2 Inlayer

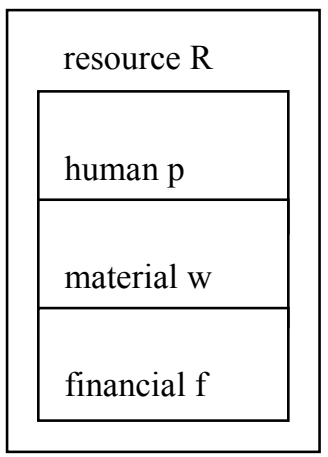

(b)

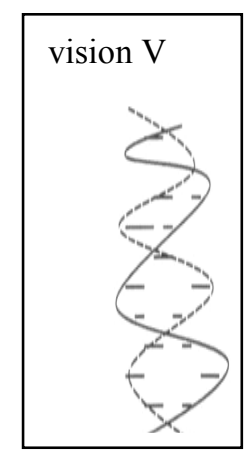

(d)
The vision of any organization or enterprise decides the enterprise mission, and the enterprise vision membrane contains the enterprise's genetic material - enterprise DNA, and the quality of DNA has a great influence on the enterprise's survival and development, so the vision must be clear, not vague, also cannot change randomly. And the vision's realization needs a series of goals to achieve, and correct strategies to choose. For any goal, needs certain resources, needs to construct and cultivate a team adapting with resources, needs to make corresponding strategies, and then achieve the goal in a proper environment. So when everything is ready, with the rule $S R T V \rightarrow[\text { Enterprise }]_{1}$, a new enterprise is born. Strategies need to change with the great change of market environment by $\left[d_{1} c_{1} m_{1} \rightarrow d_{2} c_{2} m_{2}\right]_{i}$, so that we can adjust ourselves in the increasingly cut-throat competition and to find out effective measures in time. The replication and transfer of enterprise DNA is the enterprise core values' copy and transfer process. The accurate replication of DNA with $\left[[\text { enterpriseDNA }]_{i}\right]_{i} \rightarrow\left[D N A_{1}\right]_{i}\left[D N A_{2}\right]_{j}$ guarantees the core value's correct transformation, just like the model of Mcdonald's. In the time when an enterprise cell actively makes a choice, the choice may turns to some different directions. However, choice itself is an important part in making strategies. The company's core value is actually the core teams' 
common values to the enterprise operation management. So, when any one conforms to the enterprise value, then the choice will be on behalf of all staffs' will. When the resources are not sufficient, the team's ability is without development, the environment becomes more uncertain, and in a short time finding no corresponding strategy to sharp expansion goal, any of the proposed "strategy" is a dream. With no twist, the company may be die and the resources dissolved by $[S R T V]_{i} \rightarrow$ environment . Therefore, the enterprise's survival and development is the mutual connection of the enterprise vision, strategy, resource, team and external environment.

\section{B. Communication between Enterprise Cells}

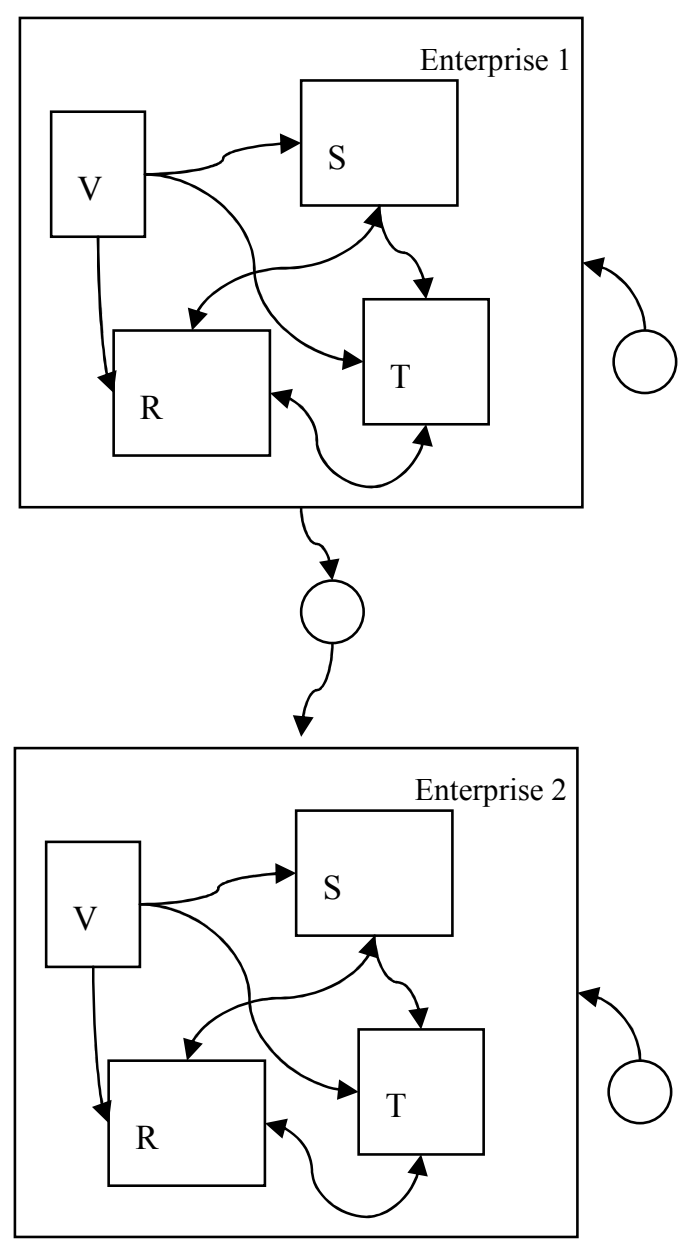

Fig.3-3 Communication between Enterprise Cells

The enterprise cells do not exist independently in the market economy environment. There will inevitably be communication and fusion between cells. Through the sending in rule $\left(u[]_{i} \rightarrow[v]_{i}\right)$, all sorts of outside resources (human, material and financial resources, etc.) continuously come into the enterprise cells. The rule is $p w f[] \rightarrow[p w f]$. The new personnel expand the enterprise group, enrich the enterprise culture. The purchase of machinery and equipment expands the production scale, and improves the product efficiency and at the same time influences the enterprise strategy for next step. Integration of capital guarantees the enterprise's unobstructed expansion, and gradually makes the enterprise do bigger. Resources come into a firm can not be used immediately, $\quad\left[p_{1} w_{1} f_{1} \rightarrow p_{2} w_{2} f_{2}\right]_{i} \quad$ and $\left[p_{1} w_{1} f_{1}\right]_{i} \rightarrow\left[p_{2} w_{2} f_{2}\right]_{j}\left[p_{3} w_{3} f_{3}\right]_{k}$ makes them in a pretty status which really work to the company. At the same time, there also exists resources outflow and output of products or services in the effect of sending out rule $\left([u]_{i} \rightarrow[]_{j} v\right)$. Staff's loss is common phenomenon, $\quad\left[h_{1} g_{1} a_{1}\right]_{i} \rightarrow[]_{j} h_{0} g_{0} a_{0}$ expresses the loss of a team, even the key leaders in some situations hop into another enterprise. Resources sharing, such as technology integration with rule like $\left[w_{1} f_{1} h_{1} g_{1} a_{1}\right]_{i} \rightarrow\left[w_{2} h_{2} f_{2} a_{2}\right]_{j}\left[f_{3} g_{3} a_{3}\right]_{k} \quad$, can also through the exchange progress to promote enterprise's symbiosis and coevolution.

\section{CONCLUSION}

From the inorganic machinery without evolution processes to organism with life, we can see that the purpose of enterprises is not simply to maximize profit, but in order to grow or stay longevity. The enterprise strategies should coexist with other components and rely on each other. Considering enterprise as cells, it has its life characteristics, and it can be the foundation and basic basis to use membrane computing theory to carry on the analysis.

By constructing enterprise cell membrane structure, using membrane rules to simulate the growth of enterprises, can be regarded as a major innovation in the point of bionics research on enterprise's development and evolution. However, its live application is not common, and the combination of enterprise development is just a theoretical exploration, the theory and application research remains to be perfect. 


\section{ACKNOWLEDGEMENTS}

This paper was finally supported by National Natural Science Foundation of China (61170038), Shandong Province Natural Science Foundation (ZR2011FM001), Humanities and Social Sciences Project of Ministry of Education (12YJA630152).

\section{REFERENCES}

[1] Ken Baskin. Enterprise DNA-Inspired from Organism. Beijing: Citic Press, 2001.

[2] Neilson Gary. Organization DNA. Strategic Finance, Nov2004, 86(5).

[3] Li G. Enterprise evolution mechanism research in the perspective of enterprise gene. Shanghai: Fudan University, 2007.

[4] Chen Z J. Enterprise's New Life. Shanghai: Fudan University Press, 2009.

[5] Qian H. Niche, Factors Interacting and Organization Evolution. Hangzhou: Zhenjiang University Press, 2008.

[6] Liu D S. Study on the Gene and Its Mechanism of Innovative Small and Medium-sized Enterprise. Shandong: Shandong University, 2011.

[7] Păun G., Computing with membranes. Journal of Computer and System Sciences, 2000, 61(1): 108-143.

[8] Păun G., Membrane Computing. An Introduction. Springer, Heidelberg. 2002.

[9] http://ppage.psystems.eu/[C].

[10] Zhang Y M, Li W W. Constructing the Internal Growth Mechanism in the Small and Medium Technical Enterprise from Bionics View. Journal of graduate school of Chinese academy of social sciences, 2009, (4): 37-41.

[11] Păun, Gh. The Oxford Handbook of Membrane Computing. Oxford University Press, Oxford.

[12] Zhou H, Peng X L. Research on Life Model of Enterprise. China Soft Science, 2000 (10).

[13] YANBIN. The Theory of Evolution for Company Reproduction. Hangzhou: Zhejiang People's Publishing House, 2010.

[14] Yang Z Z. Enterprise in ecology. Beijing: Science Press, 2003.

[15] Spiegel Eric A, Neilson Gary, Flaherty Thomas J, Ranghavan Srini. Test your company's DNA. Electric Perspectives, Mar/Apt 2005, 30(2).

\section{Creative Commons Attribution License 4.0 (Attribution 4.0 International, CC BY 4.0)}

This article is published under the terms of the Creative Commons Attribution License 4.0 https://creativecommons.org/licenses/by/4.0/deed.en US 